\title{
Non-alcoholic duct destructive chronic pancreatitis
}

N Ectors, B Maillet, R Aerts, K Geboes, A Donner, F Borchard, P Lankisch, M Stolte, J Lüttges, B Kremer, G Klöppel

Department of Pathology, Catholic University Leuven,

Belgium

N Ectors

K Geboes

Department of Abdominal Surgery, Catholic University Leuven, Belgium

R Aerts

Department of Pathology, Academic Hospital Jette, Free University Brussels, Belgium

B Maillet

Department of Pathology, University of Düsseldorf,

Germany

A Donner

F Borchard

Department of Internal Medicine, Municipal Hospital Lüneburg, Germany P Lankisch

Department of Pathology, Municipal Hospital Bayreuth, Germany

M Stolte

Department of Pathology, University of Kiel, Germany

J Lüttges

G Klöppel

Department of Surgery, University of Kiel, Germany

B Kremer

Correspondence to: Dr G Klöppel, Department of Pathology, University of Kiel, Michaelisstrasse, 1, D-24105 Kiel, Germany.

Accepted for publication 14 March 1997
Abstract

Background-The pathology of nonalcoholic chronic pancreatitis has not yet been sufficiently studied.

Aims-To identify the major changes of pancreatic tissue in patients surgically treated for non-alcoholic chronic pancreatitis.

Patients-Pancreatectomy specimens from 12 patients with non-alcoholic chronic pancreatitis, including four patients with autoimmune or related diseases (Sjögren's syndrome, primary sclerosing cholangitis, ulcerative colitis, and Crohn's disease), were reviewed.

Methods-Morphological changes were studied histologically and immunohistochemically (to type inflammatory cells) and compared with the pancreatic alterations found in 12 patients with alcoholic chronic pancreatitis.

Results-In patients with non-alcoholic chronic pancreatitis, with or without associated autoimmune or related diseases, pancreatic inflammation particularly involved the ducts, commonly resulting in duct obstruction and occasionally duct destruction. None of these features was seen in alcoholic chronic pancreatitis which, however, showed pseudocysts and calcifications.

Conclusion-The pancreatic changes in patients with non-alcoholic chronic pancreatitis clearly differ from those with alcoholic chronic pancreatitis. The term chronic duct destructive pancreatitis is suggested for this type of pancreatic disease.

(Gut 1997; 41: 263-268)

Keywords: non-alcoholic chronic pancreatitis; duct destructive pancreatitis

In Western countries, by far the most common cause of chronic pancreatitis is alcohol misuse, which is responsible for approximately $70 \%$ of cases. ${ }^{1}$ The next most frequent type is so called idiopathic chronic pancreatitis (ICP), which comprises $10-40 \%$ of all cases and has no known cause. ${ }^{2}$ In rare cases factors such as heredity, hypercalcaemia, or an autoimmune background may play a role. ${ }^{2}$ Moreover, in some parts of India and Africa there is a particular type of chronic pancreatitis that is not associated with any of the factors known in Western countries. ${ }^{2}$ This type of chronic pancreatitis occurs in children and adolescents and is thought to be caused by malnutrition.

The pathology of chronic pancreatitis is generally thought to be the same for all aetiological types. However, most descriptions refer to alcoholic chronic pancreatitis (ACP) or take only the end stage of the disease into consideration, when all types of chronic pancreatitis may look alike..$^{3-5}$ Thus, we have a good knowledge of the evolution of the morphological changes occurring in patients with ACP. However, the morphological features of the early stage of chronic pancreatitis and of developing chronic pancreatitis of the hereditary, metabolic, idiopathic, or tropical types are unknown.

A peculiar type of chronic pancreatitis which has increasingly been reported in recent years is that associated with autoimmune and related diseases such as primary sclerosing cholangitis, primary biliary cirrhosis, chronic idiopathic inflammatory bowel disease (ulcerative colitis and Crohn's disease), Sjögren's syndrome, systemic lupus erythematosus, and various combinations of these conditions. ${ }^{6-20}$ In the clinical setting of these diseases the pancreas may show changes which have been termed sclerosing pancreatitis. ${ }^{816}$ It seems, however, that similar changes may also occur in the pancreas of patients without autoimmune disease manifestations. ${ }^{21}$

Over the past few years we have collected a series of chronic pancreatitis cases that conformed to a rigorous definition of the idiopathic type or were clinically associated with autoimmune or related diseases. Many of these presented with jaundice and were treated surgically because a carcinoma of the head of the pancreas was suspected. We reviewed the histological and immunohistochemical findings in the resected pancreatic specimens from 12 patients. In particular, we compared the pancreatic changes in these patients with those described in the literature in patients with autoimmune diseases and investigated whether these changes clearly differ from those seen in patients with ACP.

\section{Materials and Methods}

We reviewed clinical records and pancreatic histopathology from a series of 12 patients with non-alcoholic chronic pancreatitis (NACP) (five women and seven men; mean age 41 years; range 17-77) who had been treated surgically, and compared the findings with pancreatectomy specimens from 12 patients with ACP (two women and 10 men; mean age 43 
TABLE 1 Monoclonal antibodies used to investigate the inflammatory infiltrate in the pancreas of patients with non-alcoholic and alcoholic chronic pancreatitis

\begin{tabular}{lll}
\hline Antigen & Source & Dilution \\
\hline MHC class I, HLA-ABC & Dako & 1 in 10 \\
MHC class II (clone Tu34), HLA-DR & Biotest-Seralc & 1 in 50 \\
MHC class II (clone Tu22), HLA-DQ & Biotest-Seralc & 1 in 10 \\
Common leucocytic antigen (clone 2B11+PD) & Dako & 1 in 50 \\
Dendritic/reticulum cells: S100 & Dako & 1 in 300 \\
Macrophages: Kp1 (CD68) (clone 3MA134) & Dako & 1 in 50 \\
T cells: UCHL1 (clone CD45RO) & Dako & 1 in 400 \\
B cells: L26 (CD20) (clone 26) & Dako & 1 in 100 \\
CD4 T cell subset: OKT4 (CD4) & Dako & 1 in 10 \\
CD4 T cell subset: Leu3a, clone SK3 (CD4) & Becton Dickinson & 1 in 2.5 \\
CD8 T cell subset: OKT8 (CD8) & Dako & 1 in 10
\end{tabular}

Becton Dickinson, Sunnyvale, CA, USA; Biotest-Seralc, Brussels, Belgium; Dako, Copenhagen, Denmark.

years; range 31-51). Four of the patients with NACP (all men; mean age 49 years; range 29-77) also had an autoimmune or autoimmune related disease: one case each was associated with Sjögren's syndrome, primary sclerosing cholangitis, ulcerative colitis, and Crohn's disease.

Tissue blocks of 14 surgical specimens from 12 patients with NACP were obtained from the files and consultation archives of the Departments of Pathology of the Catholic University Leuven, Belgium (patients 1-4, 9, and 10), the University of Düsseldorf, Germany (patients 6 and 11), the Municipal Hospital Bayreuth, Germany (patient 5), the Municipal Hospital Lüneburg, Germany (patient 7), the Academic Hospital Jette, Free University Brussels, Belgium (patient 12), and the University of Kiel, Germany (patient 8). The tissue blocks of surgical specimens from 12 patients with ACP were retrieved from the consultation archives of one of the authors (GK). All tissue samples were routinely fixed in formalin or Bouin's fixative and embedded in paraffin wax. Additional biopsy specimens from one patient (patient 9) were partly fixed in B5 (a mercury based fixative), embedded in paraffin wax, and partly freshly frozen in liquid nitrogen cooled isopentane and stored at $-70^{\circ} \mathrm{C}$ until use.

Sections ( $3 \mu \mathrm{m}$ thick) were stained with haematoxylin and eosin, periodic acid Schiff both with and without pretreatment with amylase, Masson's trichrome, and Giemsa. The anti- bodies used for the immunohistochemical stains are listed in table 1 together with the source and the reference to their specificity, where applicable. The helper/inducer $\mathrm{T}$ cell subset was identified by simultaneous application of OKT4 and Leu3a. ${ }^{22}$ Immunohistochemical staining was done on formalin, Bouin's, or B5 fixed material using the peroxidase-antiperoxidase (PAP) method. ${ }^{23}$ An indirect immunoperoxidase method was applied on $5 \mu \mathrm{m}$ thick cryostat sections that had been fixed in cold acetone and dried at room temperature for 18 hours. ${ }^{24}$

The extent of fibrosis and inflammation was recorded. Perilobular fibrosis was defined as the presence of connective tissue within the interlobular spaces, whereas intralobular fibrosis was defined as an extension of the perilobular fibrosis into the acinar tissue. The number of immunohistochemically identified $T$ (UCHL1 positive) or B (L26 positive) lymphocytes was counted around affected ducts in consecutive sections and expressed as number per high power field (hpf) $\left(\times 63-6.15 \mathrm{~mm}^{2}\right)$. Four fields, including one affected duct each, were analysed per case.

\section{Results}

CLINICAL AND RADIOLOGICAL FINDINGS

Table 2 summarises the main clinical and radiological features of the 12 patients with NACP. Half of the patients were aged 30 years or younger at initial presentation, whereas the remaining patients were $40-77$ years old. Four patients had an autoimmune or autoimmune related disease (table 2). Their mean age was 49 years (range 29-77 years). Five patients $(42 \%)$ presented with abdominal pain and notably increased serum concentrations of lipase and/or amylase. In another five patients the presenting symptom was obstructive jaundice. In two patients NACP was an incidental finding at diagnosis of a gastric ulcer (patient 4) and during follow up for ulcerative colitis (patient 10). A gastrointestinal stromal tumour (GIST) originating from the descending part of the duodenum and extending into the retroperitoneum was included in the duodeno-

TABLE 2 Main clinical data in 12 patients with non-alcoholic chronic pancreatitis

\begin{tabular}{|c|c|c|c|c|c|c|}
\hline Patient & Age & Sex & Clinical presentation & $\begin{array}{l}\text { Other } \\
\text { diseases * }\end{array}$ & Radiological findings & Surgical treatment \\
\hline 1 & 19 & $\mathrm{~F}$ & Pancreatitis & & Stenosis of duct of Wirsung & Three wedge biopsies \\
\hline 2 & 17 & $\mathrm{~F}$ & Pancreatitis & & $\begin{array}{l}\text { Compression of duct of Wirsung by hypodense, } \\
\text { hypovascular tumour }\end{array}$ & Distal hemipancreatectomy \\
\hline 3 & 40 & M & $\begin{array}{l}\text { Obstructive jaundice, } \\
\text { painless }\end{array}$ & & $\begin{array}{l}\text { Irregularities of proximal duct of Wirsung and compression } \\
\text { of distal third of bile duct }\end{array}$ & Duodeno-hemipancreatectomy \\
\hline 4 & 41 & $\mathrm{~F}$ & Incidental finding & & Compression of duct of Wirsung by hypodense tumour & Duodeno-hemipancreatectomy \\
\hline 5 & 59 & $\mathrm{M}$ & Pancreatitis & & Compression of duct of Wirsung & Duodeno-hemipancreatectomy \\
\hline 6 & 24 & $\mathrm{~F}$ & Pancreatitis & & Irregularities of duct of Wirsung & Distal hemipancreatectomy \\
\hline 7 & 20 & $\mathrm{~F}$ & $\begin{array}{l}\text { Obstructive jaundice, } \\
\text { diarrhoea }\end{array}$ & & $\begin{array}{l}\text { Echographic tumour of head of pancreas obstructing the } \\
\text { distal bile duct }\end{array}$ & Duodeno-hemipancreatectomy \\
\hline 8 & 76 & M & $\begin{array}{l}\text { Obstructive jaundice, } \\
\text { painless }\end{array}$ & & $\begin{array}{l}\text { Echographic tumour of head of pancreas obstructing the } \\
\text { distal bile duct and the duct of Wirsung }\end{array}$ & Duodeno-hemipancreatectomy \\
\hline 9 & 29 & M & $\begin{array}{l}\text { Obstructive jaundice, } \\
\text { painless }\end{array}$ & SS & Compression of duct of Wirsung and distal third of bile duct & Duodeno-hemipancreatectomy \\
\hline 10 & 30 & M & Incidental finding & UC & $\begin{array}{l}\text { Compression of duct of Wirsung and distal two thirds of } \\
\text { bile duct }\end{array}$ & Duodeno-hemipancreatectomy \\
\hline 11 & 59 & M & Pancreatitis & $\mathrm{CD}$ & Stenosis of distal bile duct & Duodeno-hemipancreatectomy \\
\hline 12 & 77 & $M$ & $\begin{array}{l}\text { Obstructive jaundice, } \\
\text { painless }\end{array}$ & PSC & $\begin{array}{l}\text { Echographic tumour of head of pancreas obstructing the } \\
\text { distal bile duct }\end{array}$ & Duodeno-hemipancreatectomy \\
\hline
\end{tabular}

$\star$ Other diseases with an autoimmune background.

SS, Sjögren's syndrome; UC, ulcerative colitis; CD, Crohn's disease; PSC, primary sclerosing cholangitis. 


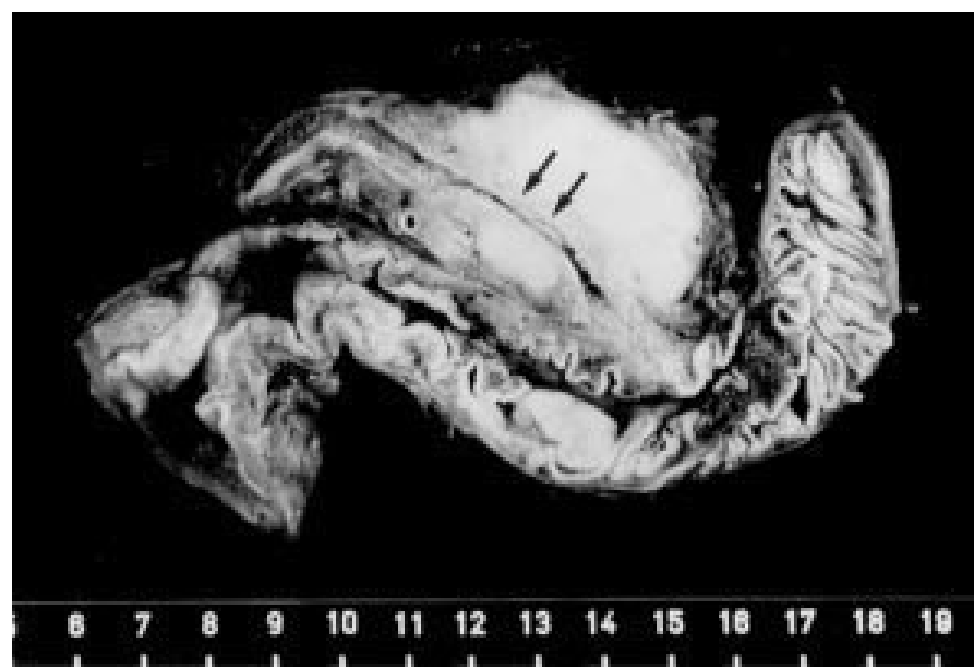

Figure 1: Gross appearance of non-alcoholic chronic pancreatitis mimicking pancreatic carcinoma (duodeno-hemipancreatectomy specimen from patient 8). On sectioning the head of the pancreas appears indurated and pale. The intrapancreatic segment of the distal bile duct is narrowed (arrows).

TABLE 3 Major histological findings in non-alcoholic chronic pancreatitis (NACP) compared with alcoholic chronic pancreatitis (ACP)

\begin{tabular}{|c|c|c|}
\hline Histological finding & $N A C P$ & $A C P$ \\
\hline Involved ducts & $\begin{array}{l}\text { Especially medium sized } \\
\text { interlobular ducts }\end{array}$ & Large interlobular ducts \\
\hline Periductal inflammation & $\begin{array}{l}\text { Conspicuous dense, infiltrating } \\
\text { epithelium }\end{array}$ & $\begin{array}{l}\text { Mild scattered, not infiltrating } \\
\text { epithelium }\end{array}$ \\
\hline Lymphocytes & Abundant $(\mathrm{T}>\mathrm{B})$ & Sparse $(\mathrm{T})$ \\
\hline Neutrophils & Present & $\begin{array}{l}\text { Present in association with } \\
\text { calculi }\end{array}$ \\
\hline Eosinophils & Present & Absent \\
\hline Plasma cells & Present & Present \\
\hline Macrophages & Present & Very rare \\
\hline Dendritic cells & Present & Very rare \\
\hline Calculi & No & Yes \\
\hline Pseudocysts & No & Yes \\
\hline
\end{tabular}

pancreatectomy resection of patient 8 . The tumour showed positivity for $\alpha$ smooth muscle actin and to a limited extent for $\mathrm{S} 100$ protein, but no histological features of malignancy. There was no radiological, surgical, or histopathological evidence that the tumour caused the pancreatitis. None of the patients had a history of cholelithiasis.

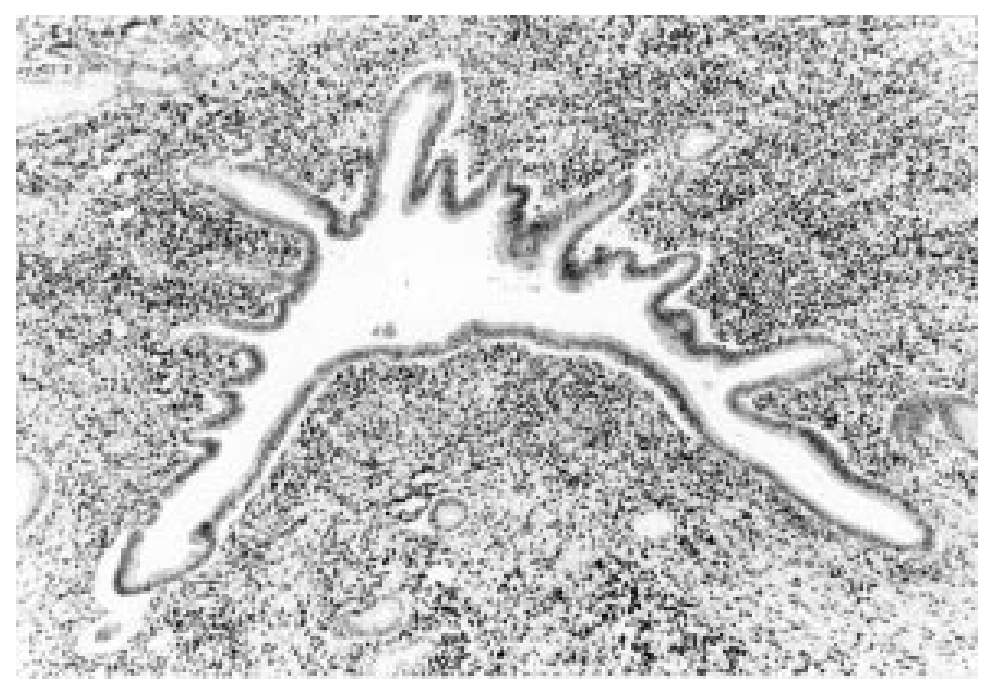

Figure 2: Non-alcoholic duct destructive chronic pancreatitis: large interlobular duct surrounded by a dense inflammatory infiltrate composed of mononuclear cells. Haematoxylin and eosin; original magnification $\times 60$.
ERCP or sonography, or both, and computed tomography revealed segmental stenosis of the main pancreatic duct in nine patients and of the terminal segment of the distal bile duct in seven. Four patients had a stenosis of both the distal bile duct and the duct of Wirsung. Ten patients (all except patients 1 and 6) were operated on for clinical or radiological, or both, suspicion of malignancy. Even on macroscopic examination of the resection specimen this suspicion persisted, as shown in fig 1.

All patients did well after operation except patient 1 , who was reoperated on for recurrent symptoms. Three years after a wedge biopsy had been performed a pancreaticojejunostomy was done. This was followed by a second pancreaticojejunostomy nine months later.

Screening for autoantibodies and hepatitis C antibodies (antinuclear $\mathrm{Ab}$, antimitochondrial $\mathrm{Ab}$, islet cell $\mathrm{Ab}$, thyroid cell cytoplasm $\mathrm{Ab}$, colloid $\mathrm{Ab}$, smooth muscle $\mathrm{Ab}$, salivary gland $\mathrm{Ab}$, colon epithelium $\mathrm{Ab}$, perinuclear antineutrophil cytoplasmic Ab (pANCA), cytoplasmic antineutrophil cytoplasmic $\mathrm{Ab}$, hepatitis $\mathrm{C})^{25-27}$ was performed in the majority of patients. The only positive finding was a response to pANCA in the serum of patient 12. Four patients suffered from autoimmune or autoimmune related diseases (table 2 ).

HISTOLOGICAL AND IMMUNOHISTOCHEMICAL FINDINGS

Table 3 summarises the most important pancreatic changes in patients with NACP. Patients with and without autoimmune related diseases had histologically and immunohistochemically comparable changes. Most conspicuous in patients with NACP were dense lymphocytic inflammatory infiltrates around interlobular ducts, especially the medium sized and large ducts (fig 2). The extent of periductal inflammation differed from duct to duct, but on average it was moderate in nine patients and severe in three. In seven patients more than $80 \%$ of the interlobular ducts were involved, including the main pancreatic duct. In the remaining patients fewer interlobular ducts were affected and the involved ducts were unevenly distributed throughout the pancreatic tissue.

The periductal inflammation focally destroyed the duct epithelium (figs 3 and 4) and led to periductal fibrosis (fig 5). These changes caused duct obliteration and fibrosis of the acinar tissue upstream from the duct lesions (fig 5). In areas with severe duct obstruction the acinar parenchyma was almost completely replaced by fibrous tissue. In all cases the degree of perilobular fibrosis was estimated to be more extensive than $(n=8)$ or equal to $(n=4)$ the degree of intralobular fibrosis. In more than half of the pancreatic specimens advanced fibrosis alternated with areas in which only periductal inflammation was found. In four patients pancreatic fibrosis narrowed the common bile duct.

Prominent obliterative phlebitis of small and medium sized veins was observed in only one patient (patient 9). Discrete lesions of the veins 


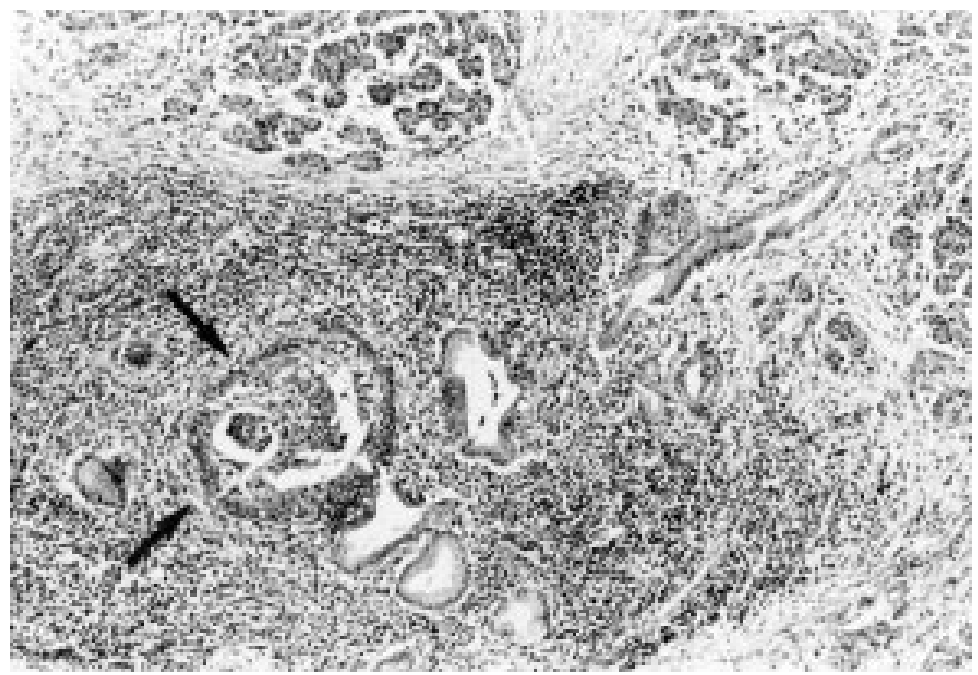

Figure 3: Non-alcoholic duct destructive chronic pancreatitis: inflammatory process destroying the epithelium (arrows) of some interlobular ducts. Haematoxylin and eosin; original magnification $\times 120$.

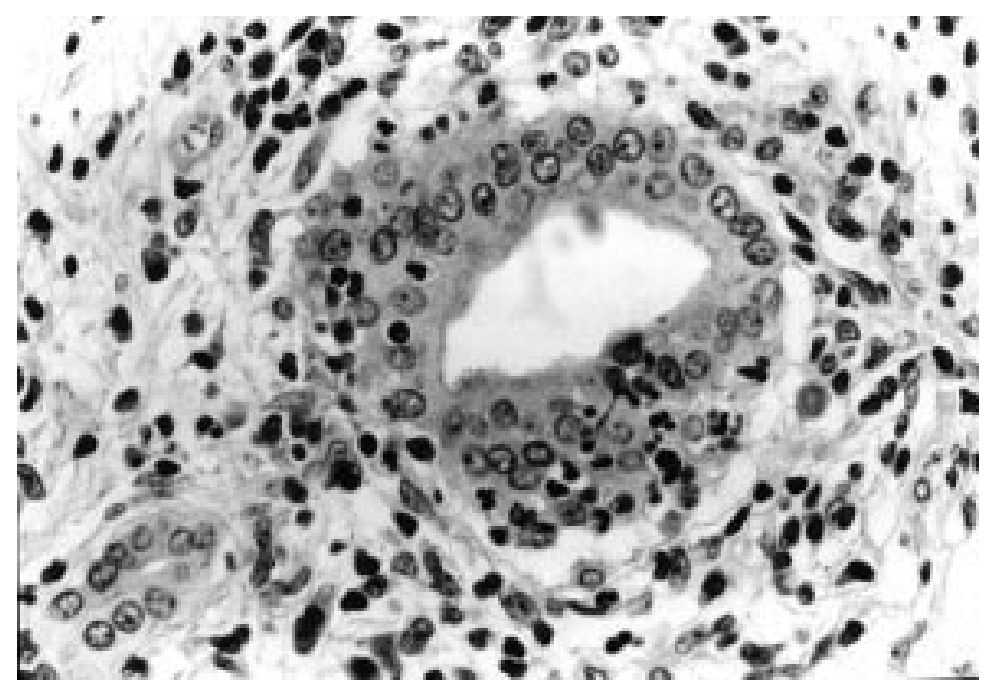

Figure 4: Non-alcoholic duct destructive chronic pancreatitis: a small interlobular duct embedded in a dense inflammatory infiltrate. The epithelium has been invaded by lymphocytes and granulocytes. Haematoxylin and eosin; original magnification $\times 240$.

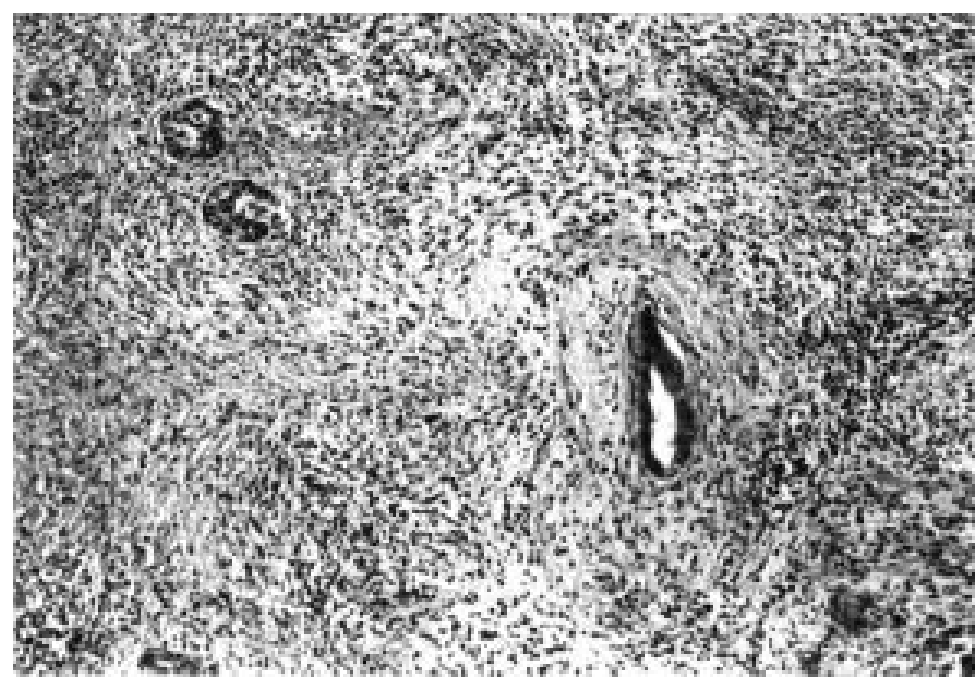

Figure 5: Non-alcoholic duct destructive chronic pancreatitis: advanced changes in the pancreas, characterised by fibrotic replacement of acinar tissue and severe duct obliteration. Haematoxylin and eosin; original magnification $\times 120$. were seen in patients 3, 6, and 11. Protein plugs, calcifications, and/or pseudocysts were not detected in any of the specimens.

The periductal infiltrates (some with lymphoid follicles) consisted of lymphocytes (common leucocytic antigen positive), plasma cells, macrophages ( $\mathrm{Kp} 1$ positive) with some admixed dendritic cells ( 100 positive), eosinophils, and neutrophils. B lymphocytes (L26 positive) were clearly less numerous than $\mathrm{T}$ lymphocytes (UCHL1 positive). The mean B lymphocyte to $\mathrm{T}$ lymphocyte ratio was 3.60:58.28 in our patients (B lymphocyte range $0-5.50$ cells per hpf; $\mathrm{T}$ lymphocyte range 14.35-121.75). In one patient (patient 10), B lymphocytes were numerous and ranged from 65 to 67 cells per hpf. The latter values were therefore not included in the calculations of means or ranges. The $T$ lymphocytes of the periductal infiltrate were CD4 (OKT4 and Leu3a positive) and CD8 (OKT8 positive) positive. $\mathrm{T}$ lymphocytes were occasionally found in the ductal epithelium itself. The epithelium of small and medium sized ducts focally expressed MHC class I (HLA-ABC positive) and II antigens (HLA-DR and HLA-DQ positive).

The ACP specimens showed diffuse perilobular fibrosis (12/12) and focal intralobular fibrosis (11/12). Classic features of ACP such as calcifications (75\%), pseudocysts $(50 \%)$, and autodigestive necrosis (34\%) were common. Both the distribution pattern and the composition of the inflammatory infiltrate differed from those seen in NACP (table 3).

\section{Discussion}

Our morphological findings suggest that all 12 patients with NACP (eight patients withchronic pancreatitis of unknown origin and four patients with associated autoimmune and related diseases) had a form of pancreatitis that is clearly distinct from ACP and probably represents a special and as yet rarely described type of pancreatitis.

The main morphological feature of this type of NACP was a conspicuous periductal inflammation that apparently caused duct obstruction and, occasionally, duct destruction. This duct related inflammation was often unevenly distributed in the pancreatic tissue, advanced lesions alternating with rather fresh appearing changes or even largely uninvolved areas. The periductal infiltrate consisted mainly of $\mathrm{T}$ lymphocytes, but always contained groups of B lymphocytes and scattered plasma cells and macrophages. Polymorphonuclear leucocytes, some of them eosinophilic, were noted at sites where the duct epithelium was ruptured and duct destruction was evident. The inflammatory process obviously induced fibrosis, which encircled the ducts and extended into the interlobular septa. Where acinar tissue was replaced by fibrosis, the adjacent interlobular ducts appeared to be severely destroyed or had even vanished, suggesting that lobular fibrosis was due to duct obstruction. So far there is no ready explanation for the vascular changes. They were, however, a striking feature in only one patient. 
When we compared the pancreatic changes of the patients with NACP with those of the ACP group, there were clear differences that suggested different pathogenic mechanisms. In ACP the ducts were distorted and often contained calcifications. Occasionally, there were also pseudocysts and autodigestive necrosis. None of these features of $\mathrm{ACP}^{3-5}$ were present in NACP. Conversely, the periductal inflammation and duct changes observed in NACP were not encountered in ACP. Moreover, there were differences in the composition of the inflammatory infiltrate. In ACP, the lymphocytic infiltrate consisted almost entirely of T lymphocytes, ${ }^{28}{ }^{29}$ whereas in NACP they also contained scattered aggregates of B lymphocytes. A feature that did not contribute to the distinction between NACP and ACP was MHC class II expression, which occurred to the same extent in both diseases and seems to be a frequent finding in chronic pancreatitis regardless of its type. ${ }^{29}$

The literature contains a number of reports describing a type of pancreatitis that seems to be comparable or even identical to what we saw in our series of patients with NACP. In 1950, Ball et $a l^{11}$ reported pancreatic changes in patients with ulcerative colitis and called this inflammatory process chronic interstitial pancreatitis. An interstitial lymphoplasmacytic infiltrate involving the ducts was found to be associated with a fibroblastic reaction. Very similar, though more extensive, alterations of the pancreas were described in a few patients with primary sclerosing cholangitis. ${ }^{7-9}$ Apart from a chronic interstitial inflammation obliterating interlobular ducts, an obliterative phlebitis of small veins was also observed in some of these cases. Recently, chronic duct destructive pancreatitis changes have been described in association with Sjögren's syndrome, but also without concomitant autoimmune or related disorders. ${ }^{1621}$

The cause of the peculiar periductal and duct destructive inflammation in the pancreas of our patients with NACP and those reported in the literature is unclear. Moreover, there seem to be no significant differences in the pancreatic changes between those patients with an autoimmune background and those without. In our series of patients with NACP we were unable to distinguish between autoimmune and non-autoimmune related changes. It therefore seems that chronic periductal and duct destructive inflammation is not restricted to a clinically evident autoimmune background, but may also occur in patients who belong to the ICP category.

The intimate relation between the chronic inflammation and the ducts observed in our series of patients with NACP suggests that the duct cells or the duct contents are the target of the inflammatory process. From a purely morphological point of view the pancreatic duct changes are very reminiscent of the bile duct changes seen in primary biliary cirrhosis or, even more so of those seen in primary sclerosing cholangitis. This striking similarity to primary sclerosing cholangitis is of particular importance, since, as we have mentioned, a number of cases reported in the literature were associated with this disease. In our series there was one such case, whereas in a second patient the involvement of the intrapancreatic part of the bile duct was very suggestive of extrahepatic primary sclerosing cholangitis. However, this latter patient had neither signs of intrahepatic primary sclerosing cholangitis, as assessed by ERCP, nor did he have antibodies such as pANCA, which may be found in up to $70 \%$ of patients with primary sclerosing cholangitis. ${ }^{30}$ Autoantibodies were tested in a number of our patients to find indications of a possible autoimmune background. Except for the antineutrophil cytoplasmic antibodies found in the patient with associated primary sclerosing cholangitis, none was detected. Antibodies against carbonic anhydrase II were not tested however. This may be of interest in view of the recent demonstration of such antibodies in patients with idiopathic chronic pancreatitis and Sjögren's syndrome. ${ }^{31} 32$

In summary, the pancreatic changes in our patients with non-alcoholic chronic pancreatitis clearly differ from those with alcoholic chronic pancreatitis. Because the described lesions are centred around the ducts and seem to be destructive in nature, we propose the term chronic duct destructive pancreatitis for this type of pancreatic disease. Although the inflammatory duct changes are suggestive of an autoimmune process, only one third of our patients showed additional autoimmune features. In the remaining patients, who by clinical definition had idiopathic chronic pancreatitis, other pathogenetic mechanisms might therefore be involved. It is likely that chronic duct destructive pancreatitis may be a specific finding in patients with idiopathic chronic pancreatitis.

The authors are grateful to Professors V Desmet, E Ponette, and $S$ Yap for their constructive comments. We thank Ms N Buelens for her expert technical assistance and Mrs K Dege for secretarial help. Part of this paper was presented at the Digestive Disease Week of the American Gastroenterological Association, San Diego, 1995, and published in abstract form (Gastroenterology 1995; 108: A351).

1 Worning $\mathrm{H}$. Incidence and prevalence of chronic pancreatitis. In: Beger HG, Büchler M, Ditschuneit H, Malfertheiner P, eds. Chronic pancreatitis. Berlin, Heidelberg: Springer Verlag, 1990: 8-14.

2 Layer P, Singer MV. Non-alcoholic-related etiologies in chronic pancreatitis. In: Beger HG, Büchler M, Ditschuneit chronic pancreatitis. In: Beger HG, Büchler M, Ditschuneit
H, Malfertheiner P, eds. Chronic pancreatitis. Berlin, H, Malfertheiner P, eds. Chronic pancrea

3 Ammann RW, Heitz PU, Klöppel G. Course of alcoholic chronic pancreatitis: a prospective clinicomorphological long-term study. Gastroenterology 1996; 111: 224-31.

4 Klöppel G, Maillet B. Pathology of acute and chronic pancreatitis. Pancreas 1993; 8: 659-70.

5 Layer P, Yamamoto H, Kalthoff L, Clain JE, Bakken LJ, Dimagno EP. The different courses of early- and late-onset idiopathic and alcoholic pancreatitis. Gastroenterology 1994; 107: 1481-7.

6 Smith MP, Loe RH. Sclerosing cholangitis-review of recent case reports and associated diseases and four new recent case reports and associated
cases. Am f Surg 1965; 110: 239-46.

7 Scully RE, Mark EJ, McNeely BU. Weekly clinicopathological exercises-case 6-1982. N Engl f Med 1982; 306: 34958.

8 Lászik GZ, Pap A, Farkas G. A case of primary sclerosing cholangitis mimicking chronic pancreatitis. Int $\mathcal{f}$ Pancreatol 1988; 3: 503-8

9 Kawagushi K, Koike M, Tsuruta K, Okamoto A, Tabata I, Fukita N. Lymphoplasmacytic sclerosing pancreatitis with cholangitis: a variant of primary sclerosing cholangitis extensively involving pancreas. Hum Pathol 1991; 22: 387-95.

10 Epstein O, Chapman RWG, Lake-Bakaar G, Foo AY, Rosalki SB, Sherlock S. The pancreas in primary biliary 
cirrhosis and primary sclerosing cholangitis. Gastroenterology 1982; 83: 1177-82.

11 Ball WP, Baggenstoss AH, Bargen JA. Pancreatic lesions associated with chronic ulcerative colitis. Arch Pathol 1950; 50: $347-58$.

12 Axon ATR, Ashton MG, Lintott DJ. Chronic pancreatitis and inflammatory bowel disease. Clin Radiol 1979; 30 179-82.

13 Seyring JA, Jian R, Modigliani R, Golfain D, Florent C, Messing B, et al. Idiopathic pancreatitis associated with inflammatory bowel disease. Dig Dis Sci 1985; 30: 1121-6.

14 Lysy J, Goldin E. Pancreatitis in ulcerative colitis. F Clin Gastroenterol 1992; 15: 336-9.

15 Lindström E, Lindström F, Von Schenck H, Ihse I. Pancreatic ductal morphology and function in primary Sjögren's synd Panceatol 1991; 8: 141-9.

16 Sood S, Fossard DP, Shorrock K. Chronic sclerosing pancreatitis in Sjögren's syndrome: a case report. Pancreas 1995; 10: 419-21.

17 Borum M, Steinberg W, Steer M, Freedman S, White P. Chronic pancreatitis: a complication of systemic lupus erythematosus. Gastroenterology 1993; 104: 613-5.

18 Waldram R, Kopelman H, Tsantoulas D, Williams R Chronic pancreatitis, sclerosing cholangitis, and sicca complex in two siblings. Lancet 1975; i: 550-2.

19 Sjögren I, Wengle B, Korsgren M. Primary sclerosing cholangitis associated with fibrosis of the submandibular cholangitis associated with fibrosis of the submandibular glands

20 Gurian LE, Keeffe EB. Pancreatic insufficiency associated with ulcerative colitis and pericholangitis. Gastroenterology 1982; 82: 581-5.

21 Marrano D, Gullo L, Casadei R, Santini D, Leone O, Campione $\mathrm{O}$. An unusual case of chronic pancreatitis of possible immune origin. Pancreas 1996; 12: 202-4.

22 van den Oord JJ, de Wolf-Peeters C, Vanstapel MJ, Desmet VJ. Improved immunohistochemical visualization of helper/ inducer T-cells by the simultaneous application of two non-crossblocking monoclonal antibodies. Stain Technology 1985; 60: 45-9.

23 Sternberger LA, Hardy PH Jr, Cuculis JJ, Meyer HG. The unlabeled antibody-enzyme method of immunohistochem- istry. Preparation and properties of soluble antigenantibody complex (horseradish peroxidase-antihorseradish peroxidase) and its use in identification of spirochetes. $f$ Histochem Cytochem 1970; 18: 315-33.

24 Mason DY, Naeim M, Abdulaziz Z, Nash JRG, Gatter KC, Stein H. Immunohistochemical labelling of cryostat sections with monoclonal antibody. In: McMichael AJ, Fabre JW, eds. Monoclonal antibodies in clinical medicine. London: Academic Press, 1982: 585-635.

25 Haddad J, Deny P, Munz-Gotheil C, Ambrosini JC, Trinchet JC, Pateron D, et al. Lymphocytic sialadenitis of Sjögren's syndrome associated with chronic hepatitis C virus liver disease. Lancet 1992; 339: 321-3.

26 Guisset M, Klotz F, Debonn JM, Vitte S. Syndrome sec et hépatite virale chronique $\mathrm{C}$ de bas grade. A propos d'une série de 50 cas. Rev Med Interne 1993; 14: 1006.

27 Pawlotsky J-M, Ben-Yahia M, Andre C, Voisin M-C, Intrator L, Roudot-Thoraval F, et al. Immunological disorders in $\mathrm{C}$ virus chronic active hepatitis: a prospective casecontrol study. Hepatology 1994; 19: 841-8.

28 Bedossa P, Bacci J, Lemaigre G, Martin E. Lymphocyte subsets and HLA-DR expression in normal pancreas and chronic pancreatitis. Pancreas 1990; 5: 415-20.

29 Jalleh RP, Gilbertson JA, Williamson RC, Slater SD, Foster CS. Expression of major histocompatibility antigens in human pancreatitis. Gut 1993; 34: 1452-7.

30 Mulder AH, Horst G, Haagsma EB, Limburg PC, Kleibeuker JH, Kallenberg CG. Prevalence and characterization of neutrophil cytoplasmic antibodies in autoimmune liver disease. Hepatology 1993; 17: 411-7.

31 Nishimori I, Yamamoto Y, Okazaki K, Morita M, Onodera $\mathrm{M}$, Kino $\mathrm{J}$, et al. Identification of autoantibodies to a pancreatic antigen in patients with idiopathic chronic pancreatitis and Sjögren's syndrome. Pancreas 1994; 9: 374-81.

32 Kino-Ohsaki J, Nishimori I, Morita M, Okazaki K, Yamamoto Y, Onishi S, et al. Serum autoantibodies reactive with carbonic anhydrase I and II in patients with idiopathic chronic pancreatitis and Sjögren's syndrome. Gastroenterology 1996; 110: 1579-86. 